\title{
Study protocol for Healthy Conversations @ Playgroup: a multi-site cluster randomized controlled trial of an intervention to promote healthy lifestyle behaviours in young children attending community playgroups
}

Stewart G. Trost ${ }^{*}$ (D), Rebecca Byrne ${ }^{1}$, Kate E. Williams², Brittany J. Johnson ${ }^{3}$, Anna Bird ${ }^{4}$, Kate Simon¹, Li Kheng Chai ${ }^{1,5}$, Caroline O. Terranova', Hayley E. Christian ${ }^{4}$ and Rebecca K. Golley ${ }^{3}$

\begin{abstract}
Background: Early childhood is a critical window for preventing obesity and chronic disease. Yet, 1 in 4 Australian children aged 5 years and under are affected by overweight or obesity; and significant proportions of children under 5 years fail to meet guidelines for diet quality, physical activity (PA), screen time, and sleep. Consequently, effective interventions to promote healthy lifestyle behaviors and prevent obesity during early childhood are needed. Community playgroups provide an opportunity for parents, carers, and children to meet in a safe and relaxed environment to play and share information. The structure, low cost and reach of playgroups provide a unique platform to engage parents in a scalable program to promote healthful lifestyle behaviors and prevent childhood obesity. However, the evidence base for the effectiveness of health promotion programs delivered in community playgroup settings is limited and lacking credible evidence from rigorously conducted randomized controlled trials.
\end{abstract}

\footnotetext{
* Correspondence: s.trost@qut.edu.au

${ }^{1}$ Faculty of Health, School of Exercise and Nutrition Science, Queensland

University of Technology at the Centre for Children's Health Research (CCHR),

South Brisbane, Queensland, Australia

Full list of author information is available at the end of the article
}

(c) The Author(s). 2021 Open Access This article is licensed under a Creative Commons Attribution 4.0 International License, which permits use, sharing, adaptation, distribution and reproduction in any medium or format, as long as you give appropriate credit to the original author(s) and the source, provide a link to the Creative Commons licence, and indicate if changes were made. The images or other third party material in this article are included in the article's Creative Commons licence, unless indicated otherwise in a credit line to the material. If material is not included in the article's Creative Commons licence and your intended use is not permitted by statutory regulation or exceeds the permitted use, you will need to obtain permission directly from the copyright holder. To view a copy of this licence, visit http://creativecommons.org/licenses/by/4.0/ The Creative Commons Public Domain Dedication waiver (http://creativecommons.org/publicdomain/zero/1.0/) applies to the data made available in this article, unless otherwise stated in a credit line to the data. 


\begin{abstract}
Methods: The Healthy Conversations @ Playgroup randomized controlled trial (RCT) aims to address the underlying behavioral risk factors for obesity by helping parents take effective steps to improve their child's dietary, PA, screen time, and sleep behaviors. The intervention program comprises 10 "healthy conversations" led by a trained peer facilitator, designed to increase parents' behavioral capability and self-efficacy to implement autonomy-supportive parenting practices. The program will be delivered biweekly during regularly scheduled playgroup sessions over 10weeks. Effectiveness will be tested in a 2-arm cluster RCT involving 60 community playgroups in three states across Australia. After baseline assessments, participating playgroups will be randomly allocated to either intervention or wait-list control conditions. Primary outcomes (vegetable intake, discretionary foods, daily PA, screen time, sleep duration, and body mass index [BMI] z-score) will be assessed at baseline, immediately post-intervention (10-weeks; T2) and 6-months post-intervention (T3). Outcomes will be assessed for differential change at T2 and T3.
\end{abstract}

Discussion: The Healthy Conversations @ Playgroup trial will rigorously evaluate a novel peer-led intervention program to promote healthful lifestyle behaviors and prevent obesity in children and families attending community playgroups. If effective, the program could be immediately scaled-up and delivered in community playgroups across Australia.

Trial registration: Trial registered 22nd January 2021 with the Australian and New Zealand Clinical Trials Registry (ACTRN12621000055808).

Keywords: Obesity, Childhood, Diet, Physical activity, Screen time, Sleep

\section{Background}

Childhood obesity continues to be one of the most serious health challenges worldwide. Globally, it is estimated that over 42 million children aged 0 to 5 years are affected by overweight or obesity [1]. In 2017-18, one in four Australian children aged 5 years or under were affected by overweight or obesity [2]. Of concern, young children with overweight or obesity are more likely to experience significant short-term health problems, including asthma, sleep apnoea, high blood pressure, musculoskeletal disorders, fatty liver disease, and insulin resistance [1,3]. Compared to peers with a healthy weight, children with overweight or obesity more frequently experience bullying or teasing at school, and are at higher risks of significant mental health issues, including depression, anxiety, and disordered eating, exacerbated by weight stigma and bias [4]. In later life, they are at greater risk of adult obesity, type 2 diabetes, heart disease, certain cancers, obstructive respiratory disease, reproductive disorders, and mental health problems $[1,3]$. Consequently, there is an urgent need for effective, scalable, and cost-effective public health interventions to promote healthful lifestyle behaviors and prevent chronic health conditions such as obesity during early childhood.

Healthy eating, regular physical activity, limited screen time, and adequate sleep during the early years are essential for optimal growth and development, cognitive functioning, and prevention of chronic health conditions [5]. Despite this, population-level surveys indicate that significant percentages of young children do not meet public health recommendations for diet quality, physical activity, screen time, and sleep. In Australia, almost half of 2- to 3-year-olds consume less than two servings of vegetables [6]; and discretionary foods such as sweet biscuits, cakes, and processed meats account for one-third of 2- to 3-year-old's total daily energy intake [7]. Only $35 \%$ of 2 - to 5 -year-olds accumulate at least $180 \mathrm{~min}$ of daily physical activity, [8] while $74 \%$ of 2 - to 4 -year-olds exceed the screen time recommendation of less than $1 \mathrm{~h}$ per day [9]. Up to $40 \%$ of Australian parents report that their infants and young children experience sleep problems and between 10 and $20 \%$ of preschool children do not meet current sleep guidelines of 11 to $14 \mathrm{~h}$ per $24-\mathrm{h}$ period [10]. Similar trends have been reported in other countries [11].

Intervention studies conducted in home, childcare, and health service settings have demonstrated that obesity-related behaviors can be improved via the promotion of autonomy-supporting parenting practices, and that the rate of change in body mass index (BMI) can be slowed [12]. However, the evidence base is incomplete and substantial gaps in knowledge remain. First, intervention studies conducted to date have primarily targeted obesity-risk behaviors in infants or pre-schoolers, but not toddlers. In a systematic review of obesity prevention trials in children 0 to 5 years, only six of the 23 intervention studies included toddlers (18-36 months) of which one was judged to be of high quality, and none reported significant reductions in BMI [13]. Second, interventions to prevent obesity during early childhood have largely ignored the contribution of sleep to maintaining a healthy weight, despite consistent evidence linking short sleep duration to excess adiposity in children [14, 
15]. Third, very few obesity prevention programs have been delivered in existing community-based parent groups where parents have already formed social networks and can learn from and support each other [12].

One such setting, are community playgroups. Community playgroups provide an opportunity for parents, carers, and children to meet in a safe and relaxed environment to play and share information [16]. Open to all families with children under school age, community playgroups present a low-cost, light-touch family support platform because they are run by volunteer parents within a local area, at minimal charge to attending families. Typically, playgroups meet for $2 \mathrm{~h}$ per week in a local community venue, sharing unstructured indoor and outdoor play and art/craft activities. Within the early childhood service system in Australia, playgroups form an important, largely universal, bridge between the maternal child health care system and formal early childhood education and care services. They are distinct from other early childhood services because a parent or carer attends with the child and remains responsible for the child during the session. Thus, community playgroups represent an ideal setting to engage parents and deliver programs and services to enhance family functioning and promote child health and wellbeing. They also offer considerable feasibility and efficiency in terms of delivering evidence-based early childhood obesity prevention programs. Community playgroups exist in over $80 \%$ of all Australian postcodes in metropolitan, regional, rural, and remote areas $[16,17]$. Recent national data indicates that over $50 \%$ of children aged $2-3$ years attend a playgroup [18].

The structure, low cost and reach of playgroups provide a unique platform to engage parents in a scalable program to promote healthful lifestyle behaviors and prevent childhood obesity. However, the existing evidence base for the effectiveness of health promotion programs delivered in community playgroup settings is limited and lacking credible evidence from rigorously conducted randomized controlled trials. In a systematic review of health promotion programs delivered in playgroups [19], only five publications included nutrition, physical activity, or screen time outcomes, and none focused on sleep. All studies were of low methodological quality, relying on single group pre-post designs and/or qualitative analysis of interviews with playgroup facilitators. Consequently, there is very limited scientific evidence to inform policy makers, service planners, and playgroup facilitators about what works and what does not work when it comes to promoting healthy lifestyle behaviors in playgroup settings.

To bridge this knowledge gap, the Healthy Conversations@ @ Playgroup study will implement and rigorously evaluate a novel peer-led intervention to promote healthful lifestyle behaviors and prevent obesity in children and families attending community playgroups. The primary aims are: 1) evaluate the effectiveness of a 10week healthy conversations intervention to improve dietary, physical activity, screen time, and sleep behaviours in children aged 0-5 years; and, 2) examine the impact of the intervention on child BMI z-score at 6-months post-intervention. As secondary aims, the effects of the intervention on parenting practices related to child obesity related behaviors will be examined. It is hypothesised that children in intervention playgroups will exhibit significantly better post intervention diet quality, physical activity, screen time, and sleep behaviors than children attending wait-listed control playgroups. We further hypothesize that children in playgroups allocated to the intervention will exhibit significantly lower BMI z-scores at 6-months post intervention than children attending wait-listed control playgroups.

\section{Methods \\ Study design}

To address the study aims, we will conduct a multi-site cluster randomized controlled trial involving 60 community playgroups operating in three states across Australia - Queensland $(n=20)$, South Australia $(n=20)$, and Western Australia $(n=20)$. After baseline assessments, participating playgroups will be randomly allocated to either the intervention or wait-list control conditions. Primary study outcomes will be assessed for differential change immediately post intervention (10-weeks; T2) and 6-months post intervention (T3). An overview of the study design, the schedule for enrolment and study assessments is shown in Table 1.

\section{Eligibility criteria}

Playgroups meeting the following inclusion criteria will be eligible to participate in the program: located within a $150 \mathrm{~km}$ radius of the Queensland Centre for Children's Health Research, Flinders University, South Australia or Telethon Kids Institute, University of Western Australia; operating as a community playgroup (that is, coordinated by parent volunteers rather than a paid facilitator); and at least four parent-child dyads willing to participate in the evaluation of the program. In each participating playgroup, all parents with children between the ages of 1 and 5 years will be invited to participate in the evaluation. Parents with multiple children within the specified age range will be asked to enroll their oldest child in the study. Parents will be excluded if they are unable to give informed consent or have insufficient literacy to complete data collection. Parents with children outside the target age range or children with chronic health conditions that may adversely influence weight status, physical activity, diet, or sleep (e.g., severe respiratory 
Table 1 Schedule of enrolment, intervention, and assessments

\begin{tabular}{|c|c|c|c|c|c|}
\hline \multirow[b]{4}{*}{ TIMEPOINT } & \multirow[b]{4}{*}{ TO } & \multicolumn{4}{|c|}{ STUDY PERIOD } \\
\hline & & \multicolumn{2}{|c|}{ Baseline and Allocation } & \multicolumn{2}{|c|}{ Post-allocation } \\
\hline & & \multirow{2}{*}{$\begin{array}{c}T 1 \\
\text { Baseline }\end{array}$} & \multirow{2}{*}{ Allocation } & $T 2$ & $T 3$ \\
\hline & & & & $\begin{array}{l}\text { End of intervention } \\
10 \text { weeks }\end{array}$ & $\begin{array}{l}\text { Follow-up } \\
6 \text { months }\end{array}$ \\
\hline \multicolumn{6}{|l|}{ ENROLLMENT: } \\
\hline Inclusion criteria & $x$ & & & & \\
\hline Eligibility screen & $\mathrm{x}$ & & & & \\
\hline Informed consent & $x$ & & & & \\
\hline Allocation & & & $\mathrm{x}$ & & \\
\hline \multicolumn{6}{|l|}{ GROUPS: } \\
\hline \multicolumn{6}{|l|}{ Intervention } \\
\hline \multicolumn{6}{|l|}{ Wait-list control } \\
\hline \multicolumn{6}{|l|}{ ASSESSMENTS: } \\
\hline $\begin{array}{r}\text { Demographic } \\
\text { information }\end{array}$ & & $\mathrm{x}$ & & & \\
\hline Primary outcomes & & $\mathrm{x}$ & & $x$ & $x$ \\
\hline Secondary outcomes & & $x$ & & $x$ & $x$ \\
\hline $\begin{array}{r}\text { Satisfaction, } \\
\text { Engagement and } \\
\text { Perceived Utility }^{1} \\
\end{array}$ & & & & $x$ & \\
\hline
\end{tabular}

Primary outcomes: daily servings of vegetables, daily servings of discretionary foods, percentage of time in moderate-to-vigorous p20hysical activity (MVPA), daily screen time, and sleep duration per $24 \mathrm{~h}$ period

Secondary outcomes: parental self-efficacy, parenting practices related to healthy eating, physical activity, screen time, and sleep

${ }^{1}$ Provided only to parents allocated to the intervention group

disease, congenital heart disease), will be able to participate in the program, but will be excluded from the evaluation.

\section{Recruitment}

All eligible community playgroups will receive information about the Healthy Conversations @ Playgroup program through their respective state-level playgroup association via social media, newsletters, email or flyers. Playgroups registering an interest in the program will be contacted by a member of the research team to further explain the project and obtain permission to visit the playgroup. If permission is granted, a research team member will attend a regular playgroup session and explain the project to all parents in attendance. Playgroups will then be given time to discuss and decide if they, as a group, would like to receive the program. If the playgroup elects to receive the program, project staff will initiate the necessary informed consent procedures. Prior to participation, full written and informed consent will be obtained from legal parents/guardians. Parents/guardians will have the option to sign a hard copy of the consent form at the session or use a QR code to access the consent form on-line and sign it electronically. This process will continue until the required number of playgroups with sufficient participants in each site are recruited.

\section{Sample size and power}

For Aim 1, the intervention effect is the net difference for change in the healthy lifestyle behaviors immediately post intervention and at 6-months follow-up. The research hypothesis is that the intervention will result in net differences of 0.5 serving of vegetables $(38 \mathrm{~g}$ per day), 1.5 servings of discretionary foods per day, $15 \mathrm{~min}$ or $2 \%$ of time in MVPA, 30 min screen time per day, and $40 \mathrm{~min}$ of sleep per $24 \mathrm{~h}$ period. The null hypothesis is a net difference of zero. For Aim 2, the intervention 
effect is the net difference for change in BMI z-score at 6-months follow-up. The research hypothesis is that the intervention will result in a difference of $0.30 \mathrm{BMI} z$ score units. The null hypothesis is a net difference of zero. For a 2-year-old at the 84th percentile or a BMI zscore of 1.0, a difference of $0.30 \mathrm{z}$-score units equates to a clinically meaningful reduction of $0.4 \mathrm{~kg}$ in excess weight.

Table 2 reports minimal detectable differences for samples of 20,30 , and 40 community playgroups per condition. All calculations were performed assuming a power of 0.80 , a 2-tailed alpha level of 0.05 , an average cluster size of six parent-child dyads, and an intracluster correlation (ICC) of 0.10 and 0.02 for the child health behaviors and BMI z-score, respectively. Standard deviation estimates for vegetable intake were based on dietary intake data from the NOURISH randomized controlled trial [20]. The standard deviations for time in physical activity and screen time were based on previously published studies in Australian children aged 0-5 years [21]. The standard deviation for sleep duration was based on published data on Australian children [10]. The standard deviation for change in BMI z-score was based on data from the NOURISH randomized controlled trial [20]. Based on these calculations, a sample of 30 playgroups per condition achieves $\geq 80 \%$ power to detect the hypothesized between-group differences for each of the primary outcomes. To offset a projected attrition rate of up to $25 \%$, an additional two children within each playgroup will be recruited, providing an overall sample of 60 community playgroups and 480 parent-child dyads.

\section{Randomization, allocation, and blinding}

Group assignment for each site will be completed by an independent statistician using an allocation sequence generated by permuted block randomization. After baseline assessments, playgroups in each site will be randomized to the next condition (intervention or wait-list control) on the list using the database randomization module in the Research Electronic Data Capture (REDCap) platform hosted at The Queensland University of Technology [22]. Trained assessors blinded to group allocation will collect the primary and secondary outcome data. Within a health behavior intervention, it is not possible to blind either the persons delivering the intervention (peer facilitators - see below) or participants; however, peer facilitators will not take part in outcome assessments.

\section{Healthy conversations @ playgroup intervention}

The Healthy Conversations @ Playgroup program aims to address the underlying behavioral risk factors for obesity and chronic disease by helping parents take effective steps to improve their children's dietary, physical activity, screen time, and sleep behaviors. Grounded in Social Cognitive Theory [23] and Self-Determination Theory [24], the intervention comprises 10 "healthy conversations", led by a peer facilitator, designed to increase parents' behavioral capability and self-efficacy to implement autonomy-supportive parenting practices related to healthy eating, physical activity, screen time, and sleep. The intervention utilizes Behavior Change Techniques to change parenting health behavior practices, as classified the Behavior Change Technique Taxonomy v1 [25]. Behavior change techniques include goal setting (behavior), problem solving, action planning, review behavior goal(s), social support (unspecified), instruction on how to perform a behavior, behavior substitution, and verbal persuasion about capability (Additional file 1). The program will be delivered biweekly, on-site during regularly scheduled playgroup sessions by trained peer facilitators over a 10-week period (which coincides with the Australian public-school term). Informed by the results of focus groups conducted in community playgroups [26], the intervention addresses five major themes, which are described in Table 3.

\section{What is a healthy conversation?}

A healthy conversation takes place opportunistically between parents attending the regularly scheduled playgroup. With the guidance of a trained peer facilitator, parents are encouraged to share and reflect on parenting challenges related to healthy eating, screen time, physical activity, and sleep with a view towards making small but important changes to improve their child's health. The

Table 2 Minimal detectable differences for child health behaviors and BMI z-score

\begin{tabular}{llllll}
\hline Study Outcome & Hypothesised Effect & Est. SD & 20 Playgroups $(\boldsymbol{n}=\mathbf{1 2 0})$ & $\mathbf{3 0}$ Playgroups $(\boldsymbol{n}=\mathbf{1 8 0})$ & $\mathbf{4 0}$ Playgroups $(\boldsymbol{n}=\mathbf{2 4 0})$ \\
\hline Veg Intake & $1 / 2$ serve, $38 \mathrm{~g} / \mathrm{d}$ & $58 \mathrm{~g} / \mathrm{d}$ & $26 \mathrm{~g} / \mathrm{d}$ & $21 \mathrm{~g} / \mathrm{d}$ & $18 \mathrm{~g} / \mathrm{d}$ \\
Discretionary Foods & $1.5 \mathrm{serv} / \mathrm{d}$ & $2 \mathrm{serv} / \mathrm{d}$ & $1 \mathrm{serv} / \mathrm{d}$ & $0.7 \mathrm{serv} / \mathrm{d}$ & $0.6 \mathrm{serv} / \mathrm{d}$ \\
$\%$ Time in PA & $2.0 \%$ & $5 \%$ & $2.2 \%$ & $1.8 \%$ & $1.6 \%$ \\
Screen Time & $30 \mathrm{~min} / \mathrm{d}$ & $75 \mathrm{~min} / \mathrm{d}$ & $33 \mathrm{~min} / \mathrm{d}$ & $27 \mathrm{~min} / \mathrm{d}$ & $24 \mathrm{~min} / \mathrm{d}$ \\
Sleep Duration & $40 \mathrm{~min} / \mathrm{d}$ & $96 \mathrm{~min} / \mathrm{d}$ & $43 \mathrm{~min} / \mathrm{d}$ & $35 \mathrm{~min} / \mathrm{d}$ & $30 \mathrm{~min} / \mathrm{d}$ \\
BMl z-score & 0.30 & 0.90 & 0.34 & 0.28 & 0.24 \\
\hline
\end{tabular}


Table 3 Description of the five healthy conversation topics and key messages

\begin{tabular}{|c|c|}
\hline Healthy conversation topics & Key messages \\
\hline \multicolumn{2}{|l|}{ Session 1 - Reducing stress at mealtimes } \\
\hline Food refusal and child hunger/fullness & $\begin{array}{l}\text { "Parent provides, child decides": Parents can provide healthy meals and snacks; and let the child } \\
\text { decide if they are hungry. }\end{array}$ \\
\hline Supporting child taste development & $\begin{array}{l}\text { Offering new or disliked foods multiple (10-12) times helps children taste and accept (or even like) } \\
\text { new foods. }\end{array}$ \\
\hline \multicolumn{2}{|l|}{ Session 2 - Limiting screens without tantrums } \\
\hline Create a family digital media plan & $\begin{array}{l}\text { Creating a 'family technology plan' helps everyone in your family balance and manage technology } \\
\text { use. }\end{array}$ \\
\hline Alternatives to screens & Limiting screen time is challenging so it helps to plan ahead and make a "toolbox" of alternatives. \\
\hline \multicolumn{2}{|c|}{ Session 3 - Supporting movement skills in children } \\
\hline Get children moving with active play & $\begin{array}{l}\text { For young children, physical activity is about active play. It does not have to involve structured or } \\
\text { planned activities. }\end{array}$ \\
\hline $\begin{array}{l}\text { When it comes to encouraging active play, } \\
\text { parents make a difference }\end{array}$ & $\begin{array}{l}\text { Parents make a difference - encourage your child to be active by watching them, participating } \\
\text { with them, and helping them discover activities they like to do. }\end{array}$ \\
\hline \multicolumn{2}{|c|}{ Session 4 - Bedtime activities and routines to support sleep } \\
\hline Creating a bedtime routine & A consistent bedtime routine can help children sleep. \\
\hline Overcoming barriers to bedtime routines & $\begin{array}{l}\text { Make the bedroom environment as "sleep friendly" as possible and enlist the support of "significant } \\
\text { others" in implementing sleep routines. }\end{array}$ \\
\hline \multicolumn{2}{|l|}{ Session 5 - Celebrating achievements } \\
\hline $\begin{array}{l}\text { Wins with food refusal and child taste } \\
\text { development }\end{array}$ & $\begin{array}{l}\text { Be confident in yourself and your ability as a parent to positively influence your child's health } \\
\text { behaviors. }\end{array}$ \\
\hline Wins with screen time, active play, and sleep & Keep up the good work and be kind to yourself! \\
\hline
\end{tabular}

conversation typically concludes with signposting to follow-up support services or information. Initially developed for use in health care settings [27], the healthy conversations approach has been successfully implemented in other settings. Most notably, this approach has been used by childcare workers in the United Kingdom to improve diet and physical activity in families experiencing socioeconomic disadvantage [28].

\section{Peer facilitators}

The intervention will be delivered by trained peer facilitators. Peer facilitators will not be researchers or health professionals, but parents who have training and/or experience in communications and group facilitation. In our pilot study, this approach was shown to be more feasible than training a volunteer parent from each community playgroup [29]. Facilitator training will involve the equivalent of a full day face-to-face skills-based workshop (hybrid in-person and video link) and biweekly video link peer support meetings to check-in and assist with fidelity maintenance across the three sites. Through skill-based learning strategies, problem-solving and role-plays, peer facilitators will be taught how to: 1) deliver each component of the intervention; 2) effective facilitation skills; 3 ) identify and overcome common barriers to program implementation; and 4) use of social media for signposts. Prior to the workshop, peer facilitators will receive a Facilitator Handbook (hard copy and electronic) which provides a complete list of open-ended questions for conversation starters, suggestions for open-ended discovery questions and prompts, suggested responses to parent comments, suggestions for wrapping up the conversation and goal setting, and copies of the social media signpost.

\section{Implementing healthy conversations at playgroup}

During each program session, the peer facilitator will lead two 10- to 15-min healthy conversations related to a specific theme. The facilitator opens the discussion with a question for the group (conversation starter) and then guides the discussion using open-ended questions and prompts. Parents are encouraged to reflect on what they currently do as parents - the actions, behaviors and strategies they use to encourage, discourage, support, or manage their child's health behaviors. Parents are encouraged to think about "what works" for them and "what they could do differently" to improve health behaviors. Through group discussion, parents collectively formulate ideas and strategies to deal with specific challenges. When necessary, the facilitator provides ideas to keep the conversation moving and on track. At the end of the discussion, the facilitator encourages parents to select a clear and achievable strategy from those discussed in the conversation to implement at home. 


\section{Signposting intervention}

Between each session, parents will receive 'signposts' directing them to information and support about the topics covered. These signposts will be delivered via social media, using private Facebook groups set up for the purpose of the program (one per site to align with differing school term dates between sites). Project staff will post content to the Facebook group two times between each session. Each post will be related to the most recent conversation topics, and may include videos, links to articles and prompts to action. The aim is to provide participants with further information on the topic, prompt action in relation to the health behavior discussed at the previous session, encourage sharing of experiences, and increase social support. Facilitators will moderate posts (e.g., remove posts, pin, or unpin posts) and respond to comments posted by parents.

\section{Wait-list control}

The intervention playgroups will be compared to a waitlist control group completing their usual playgroup sessions. Playgroups allocated to the wait-list control group will be offered the 10-week program at the conclusion of the 6-month follow-up assessment.

\section{Participant characteristics}

Demographic information will be collected at baseline using an online survey and will include child date of birth, child sex, parental age, parental education, and family structure.

\section{Primary outcomes \\ Dietary intake}

Children's dietary intake will be reported by parents using a short questionnaire developed to assess obesityrelated dietary behaviors in 1- to 5-year-olds [30]. The 13-item questionnaire asks parents to report how many times over the past 7 days their child has consumed vegetables (2 items), sweetened drinks (e.g., fruit juice, cordial/squash, soft drinks/soda, flavoured milk; 2 items) and discretionary foods (e.g., chocolate, potato crisps or savory biscuits, processed meat, sweet baked goods, takeaway foods; 7 items), as well as type of milk (1 item) and bread $(1$ item) consumed. The short dietary questionnaire has been shown to have acceptable relative validity (Spearman's rho $=0.62$ to 0.89 ) and test-retest reliability $(\mathrm{ICC}=0.80-0.97)$ [30].

\section{Physical activity}

The percentage of daily time spent in moderate-tovigorous intensity physical activity (MVPA) will be measured using the Axivity AX3 accelerometer (Axivity Ltd. Newcastle, United Kingdom). Participants will receive the accelerometer and an information pack via express mail. The pack will include an introductory letter to parents, a detailed instruction sheet, an activity monitoring $\log$ sheet to record any activity monitor removals, and a pre-paid padded envelope to return the accelerometer and $\log$ sheet to the research team. The child will be asked to wear the accelerometer on their non-dominant wrist 24-h per day for seven consecutive days (except for bathing or water-based activities).

Upon return of the accelerometer via express mail, raw accelerometer data $(50 \mathrm{~Hz})$ will be downloaded and processed into physical activity metrics using a random forest physical activity classification algorithm specifically developed for children under five [31]. This validated machine learning algorithm uses 20 features extracted from the raw tri-axial acceleration signal to classify activity type and quantify daily time spent in sedentary activities (sitting or lying down), light-intensity activities and games (slow walking, standing, standing arts and crafts), walking, running, and moderate-tovigorous intensity activities and games (active games with balls, riding bikes/scooters). In a free-living evaluation, the random forest algorithm exhibited an overall classification accuracy of greater than $80 \%$. MVPA will be calculated by summing daily time spent in walking, running, and moderate-to-vigorous activities and games.

\section{Screen time}

Children's screen time will be measured using four items from the Movement Behaviour Questionnaire (MBQ). Parents will report the amount of time their child spends: watching television programs, videos/internet clips or movies on a television, computer, or portable/ mobile device such as tablet or smartphone; and, playing games, looking at photos, or video chatting on a screenbased device such as a computer or laptop, videogame console, iPad, tablet, or smartphone. Responses will be recorded for a typical weekday and weekend day over the past week. To estimate sedentary screen time, parents will report the amount of time their child was using screens while standing or being active. Sedentary screen time will be calculated by subtracting "active" screen time from total screen time. Weekday and weekend responses will be averaged to estimate total screen time and sedentary screen time. The screen time estimates from the MBQ have been shown to exhibit excellent test-retest reliability (ICC $=0.91$ to 0.93$)$ [30].

\section{Sleep}

Sleep duration over the previous week will be parent reported using three items from the MBQ. These items assess typical day and night sleep duration and regularity of evening sleep routine. Sleep duration and regularity responses from the MBQ have been shown to exhibit excellent test-retest reliability (ICC 0.85-0.95) [30]. 
Sleep duration and quality will also be measured using data from the AX3 accelerometer. Raw acceleration signal from the wrist will be scored for sleep-wake state using the algorithm developed by Van Hees and colleagues [32].

\section{Body mass index and weight status}

Height and weight will be measured using a standard protocol. Height will be measured to the nearest $1 \mathrm{~mm}$ using a calibrated portable stadiometer (Seca 213, Hamburg, Germany)). Weight will be measured to the nearest $0.1 \mathrm{~kg}$ using a calibrated portable digital scale (Tanita Corporation, IL, USA). BMI will be calculated as body weight in kilograms divided by height in meters squared. BMI will be converted to age- and sex-specific percentiles or z-scores using the World Health Organization Growth Standards for 0 to 5 years [33].

\section{Secondary outcomes Parental self-efficacy}

Parental confidence in relation to promoting healthy eating, reducing sedentary time, and promoting physical activity will be assessed using an established tool from the Infant study [34]. The scale comprises 20 items addressing four parenting domains: 1) selfefficacy for promoting healthy eating; 2) self-efficacy for limiting non-core foods; 3 ) self-efficacy for promoting physical activity; and 4) self-efficacy for limiting screen use. Responses are recorded on a 5-point scale with endpoints ranging from 'not at all confident' to 'extremely confident'. These scales have established evidence of validity and reliability [34], with internal consistency ranging from 0.72 to 0.85 [35].

\section{Parent feeding practices}

The Feeding Practices and Structure Questionnaire (FPSQ-28) [36] will be used to measure the following two feeding constructs: 'Reward for Eating' and 'Persuasive Feeding'. Items are scored on a 5-point Likert scale with higher scores indicating greater endorsement of that practice. The FPSQ- 28 has been validated with mothers of young children ( $2-5$ years) assessing the effects of an intervention on feeding practices. The two constructs selected for this study show good internal consistency: 'Reward for Eating' $\alpha=0.89$ and 'Persuasive Feeding' $\alpha=0.73[36]$.

\section{Parental support for physical activity}

Parental support for children's physical activity will be assessed using a 5-item scale developed by Trost et al. [37]. Parents report how often they 'encourage their child to do physical activities or play sports'; 'play outside or do physical activity or sports with their child'; 'provide transportation to a place their child can do physical activity or play sports'; 'watch their child participate in sport, physical activities or outdoor games'; and, 'tell their child that physical activity is good for his or her health'. Responses are recorded on a 6-point scale with endpoints ranging from zero (never) to five (daily). In a recent study of Australian 3- to 6-year-olds, the internal consistency of the scale, as measured by Cronbach's alpha, was acceptable at 0.79 [38].

\section{Screen time parenting practices}

Two scales from the Physical Activity and Screen Time Parenting Practices Questionnaire [39] will be used to measure screen-related parenting practices: "limiting or monitoring screen time" and "use of screen time to reward/control child behavior." For the limiting or monitoring screen time scale, parents will rate statements describing how tightly they monitor their child's screen time on weekdays and weekend days. Responses are recorded on a 5-point scale with endpoints ranging from 'strongly disagree' to 'strongly agree'. For the use of screen time to reward/control child behavior scale, parents report how often they use screen time as a reward for good behavior; take away screen time as punishment for bad behavior; offer additional screen time as a reward; and use screen time to control children's behavior. Responses are recorded on a 6-point scale with endpoints ranging from 'never' to 'very often'. Both scales have evidence of internal consistency $(\alpha=0.85$ to 0.89$)$ and test-retest reliability (ICC $=0.95$ to 0.97 ) [40].

\section{Sleep parenting practices}

Parenting practices related to sleep will be measured using the consistency scale (5 items) from the Bedtime Routines Questionnaire [41]. Parents will be asked to rate how often: their child slept in the same place, went to bed at the same time; was put to bed by the same person; performed the same activities before going to bed; and performed events in the same order before going to bed. Responses are recorded on a 5-point scale with endpoints ranging from 'almost never' to 'nearly always. The bedtime consistency scale has established evidence of internal consistency ( $\alpha=0.79$ to 0.82$)$ and test-retest reliability $(\mathrm{ICC}=0.86)[40]$.

\section{Intervention Fidelity}

Following each playgroup session in which the intervention is delivered, the facilitator will complete a checklist documenting the essential elements of the program. The checklist will record overall parent attendance, the number of parents engaged in each conversation, approximate time spent in each conversation, the extent to which key messages were delivered as planned, and parents' level of engagement in the conversations. 
Facilitators will be able to note the highlights of the session as well as any challenges encountered during the session.

\section{Overall satisfaction, engagement and perceived utility}

At the conclusion of the intervention program, parents will be invited to complete a survey assessing overall satisfaction with the Healthy Conversations @ Playgroup program, engagement with the program, enjoyment of the conversations, and the perceived utility of the group conversations and Facebook posts. Parents will be asked to rate on a 5-point scale their overall satisfaction with the program (not at all satisfied, slightly satisfied, moderately satisfied, very satisfied, extremely satisfied); the usefulness of each of the five healthy conversation topics and associated Facebook posts (not at all, a little, somewhat, mostly, very); how frequently they took part in the conversations (always, usually, about half the time, seldom, never); and enjoyment of the conversations (not at all, a little, somewhat, mostly, a great deal). Parents will also be asked if they would recommend the Healthy Conversations @ Playgroup program to others and comment on their response.

\section{Statistical analysis}

Statistical analyses will follow standard principles for RCTs using two group comparisons including all participants on an intention-to-treat basis. Between-group differences in the primary and secondary outcomes will be tested using a general linear mixed model, which accounts for the clustering of parent-child dyads within playgroups. Within each model, condition, time, the condition by time interaction will be included as fixed effects, with playgroup nested within condition, parentchild dyads nested within playgroup and condition, and the playgroup by time interaction nested within condition included as random effects.

\section{Ethics}

Ethical approval has been granted from the Human Research Ethics Committee of Children's Health Queensland (HREC/19/QCHQ/66486) and administratively reviewed by The Queensland University of Technology (2000000576), Flinders University (2586) and The University of Western Australia (RA/4/20/6386). The trial has been prospectively registered with the Australian New Zealand Clinical Trials Registry (ACTRN12621000055808). Before enrolling in the trial, full written and informed consent will be obtained from legal parents/guardians. Participant data will be managed on a secured electronic database (REDCap) and hardcopy forms stored securely at the research facility.

\section{Discussion}

As concerns for the health of young children and the resultant long-term consequences increases, light-touch universal interventions with the potential for efficient scalability and high reach are needed. In Australia, playgroups have strong engagement and acceptance within the community, but to date have been an underutilised resource in terms of health promotion. The Healthy Conversations @ Playgroup program involves providing parents the knowledge, skills, and confidence to create and manage environments for their children in which healthy behaviors across multiple domains can develop and flourish. The intervention is delivered in an ecologically-valid setting in which parents are already engaged, and likely to be open to learning through a peer facilitator. Importantly, in supporting parents as the main mechanism for change, the intervention has the potential to impact multiple children in each family setting. Through social-cognitive learning approaches, its impact may be even more broad as involved parents take on new knowledge and strategies and share them with others in the playgroup even after the research has ceased. Developmentally, supporting parenting-forhealthy-behaviors in the years prior to school is critical as it is in this time period that parents have the highest opportunity to influence their children's lifestyle habits in ways that will support positive longer-term health trajectories.

\section{Abbreviations}

BMI: Body mass index; FPSQ: Feeding Practices and Structure Questionnaire; Hz: Hertz; ICC: Intra-cluster correlation; MVPA: Moderate-to-vigorous physical activity; MBQ: Movement Behaviour Questionnaire; PA: Physical activity; RCT: Randomized controlled trial; REDCap: Research Electronic Data Capture

\section{Supplementary Information}

The online version contains supplementary material available at https://doi. org/10.1186/s12889-021-11789-3.

Additional file 1: Table 1. Behavior change techniques used in the Healthy Conversations @ Playgroup intervention program.

\footnotetext{
Acknowledgements

The research team would like to thank playgroup partners in Queensland, South Australia and Western Australia for their collaboration and assistance with recruiting playgroups. We especially wish to acknowledge the work and support of Penny Allen, Alana Hitchcock and Andrew McMahon from Playgroup QLD; Craig Bradbrook, Rebecca Blunn and Alicia Beames from Playgroup SA, and David Zarb and Caroline Ince from Playgroup WA.

\section{Authors' contributions}

SGT led the development of this protocol and conceived the study. SGT, RKG, HEC, RB and KEW were applicants on the funding proposal. SGT, RKG, HEC, RB and KEW were involved in designing the trial. SGT led the development of the sample size and analysis plan. LKC assisted with the development the funding protocol and fidelity assessment methods. COT assisted with submitting the ethics application and developed the REDCap database. RB, BJJ, $A B$ and KS led the development of the training materials and training peer facilitators. All authors contributed to reviewing, editing, and approving the final version of the paper.
} 


\section{Funding}

This project is funded by the Medical Research Future Fund (MRFF) Preventative Public Health Research Initiative (2019; APP1200764). The MRFF has not contributed to the design of the study, nor will it have a role in data collection, management, analysis, and interpretation, nor in the dissemination of findings.

\section{Availability of data and materials} Not applicable.

\section{Declarations}

\section{Ethics approval and consent to participate}

Ethical approval has been granted from the Human Research Ethics Committee of Children's Health Queensland (HREC/19/QCHQ/66486) and administratively reviewed by The Queensland University of Technology (2000000576), Flinders University (2586) and The University of Western Australia (RA/4/20/6386). Prior to participation, full written and informed consent will be obtained from legal parents/guardians. Parents/guardians will have the option to sign a hard copy of the consent form at the session or use a QR code to access the consent form on-line and sign it electronically.

\section{Consent for publication}

Not applicable.

\section{Competing interests}

The authors declare that they have no competing interests.

\section{Author details}

${ }^{1}$ Faculty of Health, School of Exercise and Nutrition Science, Queensland University of Technology at the Centre for Children's Health Research (CCHR), South Brisbane, Queensland, Australia. 'Faculty of Education, School of Early Childhood and Inclusive Education, Queensland University of Technology, Kelvin Grove, Queensland, Australia. ${ }^{3}$ College of Nursing and Health Sciences, Caring Futures Institute, Flinders University, Bedford Park, South Australia, Australia. ${ }^{4}$ Telethon Kids Institute, Nedlands, Western Australia, Australia. ${ }^{5}$ Health and Wellbeing Queensland, Queensland Government, Milton, Queensland, Australia.

Received: 13 September 2021 Accepted: 15 September 2021

\section{Published online: 26 September 2021}

\section{References}

1. World Health Organization: Report of the Commission on Ending Childhood Obesity. 2016. [https://www.who.int/publications/i/item/9789241510066]. Accessed 21 Jan 2021

2. Australian Bureau of Statistics: National Health Survey: First Results, 2017-18. 2018. [https://www.abs.gov.au/statistics/health/health-conditions-and-risks/ national-health-survey-first-results/latest-release]. Accessed 21 Jan 2021.

3. Robinson SM, Crozier SR, Harvey NC, Barton BD, Law CM, Godfrey KM, et al. Modifiable early-life risk factors for childhood adiposity and overweight: an analysis of their combined impact and potential for prevention. Am J Clin Nutr. 2015:101(2):368-75. https://doi.org/10.3945/ajcn.114.094268.

4. Bacchini D, Licenziati MR, Garrasi A, Corciulo N, Driul D, Tanas R, et al. Bullying and victimization in overweight and obese outpatient children and adolescents: an Italian multicentric study. PLoS One. 2015;10(11):e0142715. https://doi.org/10.1371/journal.pone.0142715.

5. Kuzik N, Poitras VJ, Tremblay MS, Lee EY, Hunter S, Carson V. Systematic review of the relationships between combinations of movement behaviours and health indicators in the early years (0-4 years). BMC Public Health. 2017; 17(Suppl 5):849. https://doi.org/10.1186/s12889-017-4851-1.

6. Australian Bureau of Statistics: Australian Health Survey: Nutrition First Results - Foods and Nutrients, 2011-12. 2014. [https://www.abs.gov.au/sta tistics/health/health-conditions-and-risks/australian-health-survey-nutritionfirst-results-foods-and-nutrients/latest-release]. Accessed 23 Aug 2021.

7. Johnson BJ, Bell LK, Zarnowiecki D, Rangan AM, Golley RK. Contribution of discretionary foods and drinks to Australian Children's intake of energy, saturated fat, Added Sugars and Salt. Children. 2017:4(12):104. https://doi. org/10.3390/children4120104.
8. Armstrong GP, Maitland C, Lester L, Trost SG, Trapp G, Boruff B, et al. Associations between the home yard and preschoolers' outdoor play and physical activity. Public Health Res Pract. 2019;29(1). https://doi.org/10.1 7061/phrp2911907.

9. Schranz N, Olds T, Cliff D, Davern M, Engelen L, Giles-Corti B, et al. Results from Australia's 2014 Report card on physical activity for children and youth. J Phys Act Health. 2014(11 Suppl 1):S21-5. https://doi.org/10.1123/jpa h.2014-0164.

10. Price AM, Brown JE, Bittman M, Wake M, Quach J, Hiscock H. Children's sleep patterns from 0 to 9 years: Australian population longitudinal study. Arch Dis Child. 2014;99(2):119-25. https://doi.org/10.1136/archdischild-2 013-304150

11. Roman-Vinas B, Chaput JP, Katzmarzyk PT, Fogelholm M, Lambert EV, Maher C, et al. Proportion of children meeting recommendations for 24-hour movement guidelines and associations with adiposity in a 12-country study. Int J Behav Nutr Phys Act. 2016;13(1):123. https://doi.org/10.1186/s12966-01 6-0449-8.

12. Waters E, de Silva-Sanigorski A, Hall BJ, Brown T, Campbell KJ, Gao Y, et al. Interventions for preventing obesity in children. Cochrane Database Syst Rev. 2011;(12):Cd001871.

13. Hesketh KD, Campbell KJ. Interventions to prevent obesity in $0-5$ year olds: an updated systematic review of the literature. Obesity (Silver Spring, Md). 2010;18(Suppl 1):S27-35

14. Chen X, Beydoun MA, Wang Y. Is sleep duration associated with childhood obesity? A systematic review and meta-analysis. Obesity (Silver Spring, Md). 2008:16(2):265-74

15. Taylor BJ, Heath A-LM, Galland BC, Gray AR, Lawrence JA, Sayers RM, et al. Prevention of Overweight in Infancy (POI.nz) study: a randomised controlled trial of sleep, food and activity interventions for preventing overweight from birth. BMC Public Health. 2011;11(1):942. https://doi.org/10.1186/14 71-2458-11-942.

16. Playgroup Australia. Playgroup Australia 2019. Annu Rep. 2019; [https://pla ygroupaustralia.org.au/resource/2019-annual-report/]. Accessed 02 Feb 2021.

17. Playgroup Australia: Independent cost benefit analysis of community playgroups. 2019. [https://www.pc.gov.au/_data/assets/pdf_file/0017/24 5033/sub032-nt-children-attachment1.pdf]. Accessed 23 Aug 2021.

18. Hancock K, Lawrence D, Mitrou F, Zarb D, Berthelsen D, Nicholson J, et al. The association between playgroup participation, learning competence and social-emotional wellbeing for children aged four-five years in Australia. Australas J Early Childhood. 2012;37(2):72-81. https://doi.org/10.1177/183693 911203700211.

19. Okely $T$, Trost $S$, Flood V, Cliff $D$, Kelly $B$, Jones $R$, Janssen $X$, Grossek $A$, Ellis $Y$, Alex Miller $\mathrm{K}$ : Outcomes and their measurement in playgroup programs: an evidence check rapid review. Prepared for the Sax Institute on behalf of the NSW Office of Preventive Health 2013.

20. Daniels LA, Mallan KM, Nicholson JM, Thorpe K, Nambiar S, Mauch CE, et al. An early feeding practices intervention for obesity prevention. Pediatrics. 2015;136(1):e40-9. https://doi.org/10.1542/peds.2014-4108.

21. Okely AD, Trost SG, Steele JR, Cliff DP, Mickle K. Adherence to physical activity and electronic media guidelines in Australian pre-school children. J Paediatr Child Health. 2009;45(1-2):5-8. https://doi.org/10.1111/j.1440-1754.2 008.01445.x

22. Harris PA, Taylor R, Minor BL, Elliott V, Fernandez M, O'Neal L, et al. The REDCap consortium: Building an international community of software platform partners. J Biomed Inform. 2019;95:103208. https://doi.org/10.1016/ j.jbi.2019.103208.

23. Bandura A. Social foundations of thought and action: A social cognitive theory. Englewood Cliffs: Prentice-Hall; 1986

24. Ryan RM, Deci EL. Parenting and the facilitation of autonomy and wellbeing in development. In: Self-Determination Theory: Basic psychologival needs in motivation, development, and wellness. New York: The Guildford Press; 2017. p. 319-50. https://doi.org/10.1521/978.14625/28806.

25. Michie S, Richardson M, Johnston M, Abraham C, Francis J, Hardeman W, et al. The behavior change technique taxonomy (v1) of 93 hierarchically clustered techniques: building an international consensus for the reporting of behavior change interventions. Ann Behav Med. 2013;46(1):81-95. https:// doi.org/10.1007/s12160-013-9486-6.

26. Fuller AB, Byrne RA, Golley RK, Trost SG. Supporting healthy lifestyle behaviours in families attending community playgroups: parents' perceptions of facilitators and barriers. BMC Public Health. 2019;19(1):1740. https://doi.org/10.1186/s12889-019-8041-1. 
27. Black C, Lawrence W, Cradock S, Ntani G, Tinati T, Jarman M, et al. Healthy conversation skills: increasing competence and confidence in front-line staff. Public Health Nutr. 2014;17(3):700-7. https://doi.org/10.1017/S1368980012 004089.

28. Barker M, Baird J, Lawrence W, Jarman M, Black C, Barnard K, et al. The Southampton initiative for health: a complex intervention to improve the diets and increase the physical activity levels of women from disadvantaged communities. J Health Psychol. 2011;16(1):178-91. https:// doi.org/10.1177/1359105310371397.

29. Fuller A. Development and evaluation of an intervention targeting parenting practices associated with obesity-related behaviours in young children attending playgroup. PhD; 2020.

30. Zarnowiecki D, Byrne R. New rapid assessment tools to measure obesity related behaviours in 0-5 years olds. Paper presented at the Australia and New Zealand Obesity Society Conference 2021. Brisbane; 2021.

31. Ahmadi MN, Pavey TG, Trost SG. Machine learning models for classifying physical activity in free-living preschool children. Sensors. 2020;20(16):4364. https://doi.org/10.3390/s20164364.

32. van Hees VT, Sabia S, Jones SE, Wood AR, Anderson KN, Kivimäki M, et al. Estimating sleep parameters using an accelerometer without sleep diary. Sci Rep. 2018;8(1):12975. https://doi.org/10.1038/s41598-018-31266-z.

33. WHO Multicentre Growth Reference Study Group. WHO child growth standards based on length/height, weight and age. Acta Paediatr Suppl. 2006:450:76-85. https://doi.org/10.1111/j.1651-2227.2006.tb02378.X.

34. Campbell KJ, Hesketh KD, Silverii A, Abbott G. Maternal self-efficacy regarding children's eating and sedentary behaviours in the early years: associations with children's food intake and sedentary behaviours. Int J Pediatr Obes. 2010;5(6):501-8. https://doi.org/10.3109/17477161003777425.

35. Chen JL, Guo J, Esquivel JH, Chesla CA. Like mother, like child: the influences of maternal attitudes and behaviors on weight-related health behaviors in their children. J Transcult Nurs. 2018;29(6):523-31. https://doi. org/10.1177/1043659617736883.

36. Jansen E, Williams KE, Mallan KM, Nicholson JM, Daniels LA. The feeding practices and structure questionnaire (FPSQ-28): a parsimonious version validated for longitudinal use from 2 to 5 years. Appetite. 2016;100:172-80. https://doi.org/10.1016/j.appet.2016.02.031.

37. Trost SG, Sallis JF, Pate RR, Freedson PS, Taylor WC, Dowda M. Evaluating a model of parental influence on youth physical activity. Am J Prev Med. 2003;25(4):277-82. https://doi.org/10.1016/S0749-3797(03)00217-4.

38. Trost SG, Brookes DSK. Effectiveness of a novel digital application to promote fundamental movement skills in 3- to 6-year-old children: a randomized controlled trial. J Sports Sci. 2021;39(4):453-9. https://doi.org/1 0.1080/02640414.2020.1826657.

39. Vaughn $A E$, Hales D, Ward DS. Measuring the physical activity practices used by parents of preschool children. Med Sci Sports Exerc. 2013;45(12): 2369-77. https://doi.org/10.1249/MSS.0b013e31829d27de.

40. Goncalves WSF, Byrne R, de Lira PIC, Viana MT, Trost SG. Psychometric properties of instruments to measure parenting practices and children's movement behaviors in low-income families from Brazil. BMC Med Res Methodol. 2021;21(1):129. https://doi.org/10.1186/s12874-021-01320-y.

41. Henderson JA, Jordan SS. Development and preliminary evaluation of the bedtime routines questionnaire. J Psychopathol Behav Assess. 2010;32(2): 271-80. https://doi.org/10.1007/s10862-009-9143-3.

\section{Publisher's Note}

Springer Nature remains neutral with regard to jurisdictional claims in published maps and institutional affiliations.

Ready to submit your research? Choose BMC and benefit from:
- fast, convenient online submission
- thorough peer review by experienced researchers in your field
- rapid publication on acceptance
- support for research data, including large and complex data types
- gold Open Access which fosters wider collaboration and increased citations
- maximum visibility for your research: over 100M website views per year
At BMC, research is always in progress.
Learn more biomedcentral.com/submissions

